\title{
EL PROBLEMA CATALÁN Y EL SER DE ESPAÑA
}

ANTONIO TORRES DEL MORAL 



\title{
EL PROBLEMA CATALÁN Y EL SER DE ESPAÑA
}

\author{
ANTONIO TORRES DEL MORAL \\ Catedrático de Derecho Constitucional - UNED
}

España es seguramente un ejemplo, si no único, sí destacado en el panorama mundial de un pueblo que polemiza sobre su ser, sobre su esencia, por no conocerla a ciencia cierta y porque los creadores de opinión divergen en sus análisis, no siempre desinteresados, lo cual es un infalible salvoconducto para ir a la deriva en el (des)concierto de las naciones. El «noventayochismo» (un Unamuno, un Ganivet, un Maeztu; también, a su modo, un Azorín) se caracterizó, entre otras señas de identidad, por bucear en las de España. Viniendo más acá, la autocuestión sobre el ser de España no cesó en la Dictadura primoriverista, ni en la Segunda República ni en la larga y ancha travesía del desierto franquista. Son de frecuente cita las diferencias entre Claudio Sánchez Albornoz y Américo Castro sobre el ADN al que debíamos fidelidad. Como después las protagonizadas por la obra de Laín Entralgo España como problema, que encontró réplica en España sin problema, de Calvo Serer, cuando éste todavía no se había transmutado en el incómodo dueño del benemérito diario Madrid.

Fue alcanzar nuestro país un cierto grado de desarrollo económico y político y olvidarnos de aquellas primeras polémicas. En cuanto a la última, poco después se le encontró su tratamiento preciso: «España es el problema y Europa la solución», frase que concitó inteligencias y voluntades múltiples y variadas y que, sin embargo, lleva ahora trazas de no haber sobrepasado la categoría de eslogan, de uno más al servicio de la palabrería.

¿Se trataba de un cierre en falso? En llegando las penurias económicas, sazonadas por la insufrible corrupción de una buena parte de la clase política, ya se pone en duda de nuevo el ser de España y nos preguntamos otra vez cuál es su problema, nuestro problema como nación. Y en esas estamos. 
Durante el proceso constituyente ya se discutió sobre la condición de España como nación integrada por regiones, o por regiones y nacionalidades, o por naciones. El precario acuerdo quedó en el punto medio, pero fue ganando terreno la última definición, a la que se apuntaron incluso Comunidades Autónomas abanderadas del españolismo. Desde hace unos años se vuelve a la carga extremando la perspectiva: una de las autoproclamadas naciones (a la que seguirá a no mucho tardar alguna otra) pretende separarse del hasta ahora tronco común y navegar por el ancho mundo como soberana. Con la agravante de que crece el número de ciudadanos que, mientras unos también ponen en entredicho la solución europea, otros la niegan, y otros, en fin, reformulan el dicho: «Europa es la solución... cuando deje de ser problema».

El caso es que escribo azotado por los aires convulsos que han revuelto España hasta dejarla irreconocible. Aires de corrupción que hacen irrespirable el régimen democrático que tanto esfuerzo, patriotismo y pericia costó, obra de una clase política benemérita sobre la que ahora se arrojan indecorosas sospechas; democracia a cuyo alumbramiento y primeros pasos asistimos con tanta ilusión. Son también aires de rencor que amenazan con despiezar lo que con tanto trabajo lograba mantenerse unido. Son, en fin, aires de injusticia y de insolidaridad que permiten a unos vivir con un lujo pagado con dinero del común y condenan a otros a regresar a casa de sus padres por haber sufrido un desahucio por parte de un banco reflotado con su propio dinero. Malos tiempos y no sólo para la lírica.

A la vista del resultado, nos preguntamos qué es lo que hemos hecho mal. También ha habido cosas bien hechas, pero éstas no cuentan porque es lo obligado. Alguna cosa discutible se hizo en la construcción general del Estado autonómico, saludado inicialmente como un verdadero hallazgo constitucional, y varias en el inmediato siguiente.

En el periodo constituyente, se procuró atraer a los líderes nacionalistas vascos al consenso generalizado plasmando en la Constitución unos derechos históricos del País Vasco, medida que, sin embargo, no satisfizo ni a unos ni a otros. En cuanto al resto del mapa autonómico, la aventura comenzó a torcerse cuando se dio entrada a las excepciones: Andalucía, Valencia, Canarias y Navarra, cuyos respectivos procesos de institucionalización como Comunidades Autónomas, sin que yo me pronuncie aquí sobre su justicia o injusticia, fueron manifiestamente irregulares.

Lejos de mi intención decir que el Estado autonómico ha sido un rotundo fracaso, pero a condición de que no se le quiera calificar como un éxito indiscutible. Ha funcionado pasablemente bien con reservas, es decir, lejos de las expectativas despertadas durante el proceso constituyente. 
En tiempos tales, de egoísmo y darwinismo social, son de agradecer gestos como el de Rosa María Fernández Rivera y Esther González Hernández, que han empleado cientos de horas a lo largo de varios años y una alta sobredosis de solidaridad para poner en las librerías un producto útil para todos nosotros: el meritorio volumen -y voluminoso es- que, bajo el aséptico título de Cataluña en sus documentos, nos ofrece lo que futuros investigadores necesitarán para estudios sucesivos acerca de lo que ya se ha dado en denominar «el problema catalán» ${ }^{1}$. Porque la política tiene lugar en la Historia. El Derecho es un producto histórico. La Historia es, pues, imprescindible en el conocimiento de la política y del Derecho, del Derecho político, que es algo más extenso que el estricto Derecho constitucional. Si la Historia es madre de la ciencia, más, mucho más lo es respecto de estas dos áreas.

Por eso quiero desde aquí agradecer la sugerencia que me hicieron las autoras de dedicarle a su obra un comentario en esta Revista, y más en estas horas, cuando parece que la solución de los problemas de inserción o encaje de Cataluña en España está más lejos que nunca².

Muchos españoles estamos transidos por una doble sensación. De un lado, surge por doquier sensación de vértigo como si nos despeñáramos inexorablemente y en breve plazo, tal es la rapidez trepidante de los acontecimientos. De otro, la de una inerte pérdida de tiempo; la pregunta se ha generalizado: pero ¿qué hacen los poderes públicos que no abordan de una vez el problema sino que le dan vueltas al atajo, dicho sea en términos machadianos?

Si digo que la construcción del Estado autonómico fue la apuesta más importante que hizo el constituyente español en 1978 no hago sino repetir lo que con anterioridad se ha podido leer en cientos de publicaciones y reiterado en congresos, jornadas y seminarios. Pero añado otra verdad bien sabida: que la deriva de las autoridades catalanas en los últimos años prestan a dicha apuesta un perfil incómodo para los ciudadanos en general y para los juristas en particular, salvo obviamente los políticamente alineados con ella. Así, pues, el «problema catalán» se ha convertido en el más espinoso desde la transición de la dictadura a la democracia y, al parecer, el que menos se presta a una solución airosa y a gusto de todos. Eso ya no es posible.

Las dos sensaciones tienen su porqué. La primera por los continuos palos de ciego que dan unos y otros confundiendo las más de las veces la identidad de su

1 Fernández Rivera, R. M. y González Hernández, E., Cataluña en sus documentos, Centro de Estudios Políticos y Constitucionales, Madrid, 2013, p. 1328.

2 Cuando estas páginas vean la luz, habrán tenido lugar tanto las elecciones al Parlamento catalán y acaso también las generales a Cortes y pueden haber variado un tanto los datos de una a otra. Culpa es del que suscribe, que no ha puesto la diligencia necesaria para publicarlas antes. 
adversario. La segunda por el contumaz olvido de lo importante en función de lo urgente, por la preferencia de lo accidental sobre lo sustancial, por la inagotable escalada verbal tan huera que impide todo intento de diálogo, sustituido una vez y otra por monólogos tan intelectualmente pobres como enfáticamente pronunciados. De un lado, algunos se alarman por la posibilidad de acabar procesados por organizar una atípica consulta popular para la que no tenían competencia; de otro, los hay que se sumen en el tedio a la vista de tanta inoperancia e ineptitud, de tanto silencio estéril sustituido a veces por tanta palabrería. Unos se ofrecen como mártires, incluso incitando al imaginario verdugo a cobrar la pieza; otros repiten mensajes monocordes invariablemente vacíos. Y, en medio, el problema intacto y una ciudadanía perpleja. Unos acusando a España de robar a su Comunidad Autónoma, pero gastando ella todo lo indecible en televisiones ruinosas, en embajadillas ilegales y en consultas prohibidas mientras adoptan una actitud tancredista ante honorables ladrones (a los que, ay, tanto deben), los cuales, como muestra de amor a su patria chica y grande, se llevan el dinero robado a paraísos fiscales extranjeros. Otros acusando a los líderes catalanes de haber dado hace tiempo el paso hacia el suicidio político a lomos de la mentira doliente.

Probablemente no hay en la Historia un ejemplo tan elocuente de diálogo de sordos porque cada cual ningunea al adversario, le niega la existencia, o la capacidad, o la propia intención dialogante. Parece como si se quisiera priorizar las amenazas, las mofas y los desplantes sobre el diálogo. Es difícil encontrar un desencuentro semejante en el panorama actual europeo.

Inmediatamente el lector de la obra de referencia irá apreciando sus valores. Pretenden las autoras ofrecer una herramienta con la que facilitar una visión de Cataluña desde una perspectiva jurídico-política. Un libro como éste, hecho con entusiasmo desapasionado, invita a la reflexión serena sin -todavía- vencedores ni vencidos, y ojalá no los haya nunca. Es un libro que cuenta cosas, refresca el pasado sine ira et studio, aportando datos, hechos, episodios; se encuentra en él todo lo que dio de sí el tiempo acotado por las autoras: documentos originales, algunos de difícil acceso, transcripciones fidedignas que hacen legibles grafías antiguas y un generoso etcétera a lo largo de casi un millar y medio de páginas.

Al comienzo de ellas encontrará un extenso Estudio Preliminar, de carácter meramente expositivo por libre decisión de las autoras, aunque nadie mejor que ellas para haber hecho análisis jurídicos y políticos, sincrónicos y diacrónicos, porque dominan el material por el derecho y por el envés. Manejando una bibliografía correctamente seleccionada para el objetivo de la publicación, las autoras han preferido la autocontención, apuntando asuntos y problemas y comentándo- 
los pero sin discutirlos detenidamente por entender que la finalidad del libro es la de oferta de material para que el lector elabore por sí mismo su propio criterio.

Un reproche sí he de hacer, que es extensivo a la mayoría de los autores que tratan nuestro constitucionalismo histórico. Si éste ya es de por sí tortuoso y lamentable, lo parece mucho más si incluimos entre sus textos fundamentales el documento perpetrado en Bayona por el soberbio Corso, bien pertrechado por el ejército más poderoso del mundo, frente a un pueblo pobre, inerme y analfabeto y una familia regia felona y degenerada. Texto, además, técnicamente paupérrimo, redactado a mayor gloria del Emperador con su obediente hermano como pelele impuesto por él al frente del Estado español para su más fácil manejo al servicio de sus planes imperialistas. Mientras tanto, la genuina (hasta donde se podía dado el estado de guerra) representación política española, refugiada en Cádiz, daba una soberana lección de constitucionalismo elaborando un texto que fue bandera del liberalismo europeo.

Las autoras han dedicado muchas horas de trabajo en recopilar 126 documentos originales, fruto de un «exhaustivo buceado» en archivos de instituciones públicas y privadas, con lo que nos ofrecen a los estudiosos interesados un material apto para adquirir un mejor conocimiento de la historia del problema, que es la mejor vía, salvo empecinamiento en contrario, para su más correcto planteamiento.

Se trata de documentos, fundamentalmente normativos, aunque los hay de naturaleza sociopolítica, pero siempre con potencial jurídico. Son presentados unos en castellano y otros en catalán, y distribuidos en cinco etapas. La primera trata del catalanismo durante la Restauración y comienza en 1883, con el Projecte de Constitució de l'État Catalá. La segunda corresponde a la II República, y, pasando por los mal llamados cuarenta años (Umbral) del régimen franquista y por la etapa preconsitucional y constitucional que denominan «transición catalana» (que se extiende desde lo que se conoce como «antesala del Estatuto de 1979» hasta su aprobación y posterior desarrollo), desemboca en las elecciones catalanas de 2003 y en el Estatuto de 2006. Este fue planteado en un primer momento como reforma de su predecesor de 1979 y mantenido así en su denominación oficial, pero es manifiestamente un Estatuto de nueva planta, dicho sea sin querer hacer un juego de palabras, por cuanto casi cuadruplica el número de preceptos de su aquél. Es un recorrido a través de 123 años, que, por despiste o hipérbole, las autoras describen como «más de dos siglos de historia».

Como se desprende de los datos que preceden, se cierra el libro en 2006, entre otras razones para, prudentemente, «huir de momentos o coyunturas sociopolíticas de profunda queja, victimismo o acusaciones cruzadas de los 
protagonistas». Pero la realidad nos ha traído hasta donde estamos, justo en esa vorágine, en unas horas en las que la reflexión deja paso al reproche, al exabrupto y al sarcasmo y que, por eso mismo, no son las más propicias para el análisis sereno, ni para la adopción de decisiones, que nunca deben tomarse con los ánimos alterados.

Pero, centrando el problema en Cataluña, no podemos decir que los males vengan de entonces. Atendamos a unos hechos bien conocidos y significativos, aunque poco recordados:

1. Durante el proceso constituyente, en ningún momento presentó el nacionalismo catalán solvente reivindicaciones semejantes a las que exigía con énfasis y negociaciones extenuantes el nacionalismo vasco: ni derechos históricos, ni concierto económico, ni pacto con la Corona.

2. La meta del nacionalismo catalán convergente se cifraba en un principio en el restablecimiento del Estatuto de 1932 y la tenía ya prácticamente alcanzada con el restablecimiento de la Generalitat. A más a más, por decirlo al modo catalán, el Estatuto de 1979 aumentaba exponencialmente su cuota de autogobierno.

3. Los continuos Gobiernos de Convergencia y Unión han contribuido de manera políticamente aceptable a la gobernabilidad de España durante dos décadas prestando apoyo a sucesivos Gobiernos nacionales, a la izquierda y a la derecha, cuando se encontraban en circunstancias de cierta precariedad. A su vez, hasta comienzos de este siglo, ese nacionalismo catalán moderado, teniendo a la zaga un independentismo con números electorales escasos, ha gobernado Cataluña con comodidad, para la que no le ha faltado la complicidad (o intercambio de apoyos) del Gobierno nacional, no desencadenando ningún desencuentro con tal de que lo dejaran profundizar en la catalanización de la sociedad que gobernaban.

4. Pero iban detectándose ciertos agujeros negros, algunos muy notables en materia de educación, cultura y lengua, y, según se sabe ahora, por increíbles dosis de corrupción eficazmente silenciada con la complicidad de los propios Gobiernos nacionales y por las demás fuerzas políticas, tanto de las que contaban con implantación nacional, como por las autonómicas supuestamente antagonistas.

5. Las hostilidades se desataron con ocasión del Estatuto de 2006, texto que se envenenó por la oferta enormemente imprudente del Presidente de Gobierno nacional, Sr. Rodríguez Zapatero, de respaldar a todo evento el nuevo texto que aprobara el Parlamento Catalán, en el que tenía mayoría absoluta un Gobierno tripartito de izquierdas presidido por un incontrolable Señor Maragall. 
Dado que después no fue así por su extraordinaria desmesura, apareció una línea cuando, modificado el texto a la baja (con la colaboración, todo hay que decirlo, del nuevo Gobierno autonómico, de nuevo nacionalista), fue aprobado por las Cortes y por referendo autonómico pero algunos de sus preceptos, a su paso por el Tribunal Constitucional, fueron invalidados y otros desactivados por su reinterpretación a la baja.

6. Por cierto que en tal Estatuto sí aparecen, para sorpresa de muchos, unos denominados derechos históricos de los que nadie tenía noticia hasta la fecha y que nunca fueron esgrimidos por el nacionalismo catalán ni en el proceso constituyente, ni en el estatuyente, ni durante los largos y anchos años de gobierno nacionalista.

7. Desde entonces para acá no ha sido posible, o no se ha sabido, recuperar el imprescindible clima de confianza repara el correcto funcionamiento de un Estado territorialmente descentralizado. Antes al contrario, hemos asistido a una escalada verbal, jurídica y fáctica cuyo colofón ha sido la celebración de un pseudorreferendo de autodeterminación, previamente suspendido por el Tribunal Constitucional y la celebración de unas segundas elecciones autonómicas en clave plebiscitaria que, en caso de resultado positivo (las primeras no lo fueron), serían unilateralmente interpretadas como habilitación democrática para la declaración de independencia. Todo un cúmulo de despropósitos políticos y de desatinos jurídicos.

No creo inoportuno en absoluto hacer público aquí y ahora un episodio vivido por mí hace treinta años y del que apenas he hablado en un par de ocasiones. Invitado a pronunciar una conferencia en una institución universitaria catalana, lo hice como suelo: con un análisis lealmente crítico de la parcela que se me había asignado de la Constitución española. Ya tenía yo escrito en mis Principios de Derecho Constitucional que deseaba que ésta fuera, con las reformas que fueren necesarias, la última Constitución de la nación española. Mi lealtad constitucional no podía ni puede ser puesta en entredicho, pero tampoco se puede eliminar mi resuelta libertad científica. Al término de la sesión y estando ya a solas, la persona que me había invitado, me recriminó con dureza el talante crítico de mi intervención. Sorprendido por una admonición que no había sufrido ni siquiera durante el ominoso régimen franquista, le pregunté si es que en materia constitucional había censura en Cataluña. Respuesta: «Tómalo como quieras, pero aquí, en Cataluña, no se puede criticar la Constitución, porque es nuestra Constitución, por la que hemos luchado durante más de un siglo; es la Constitución de nuestra libertad como pueblo. Así que ya lo sabes». 
Si eso era así hace treinta años, ¿cómo y por qué hemos llegado a la situación actual?

La lectura del libro de referencia nos ayudará a reconocer nuestra (hasta ahora) singular torpeza para plantear y resolver el más grave problema que tiene planteado la España constitucional. 